\title{
Penerapan Fuzzy Tsukamoto Dalam Usaha Katering
}

\author{
Dwita Elisa Sinaga1, Sri Anita Siallagan², Halimatusakdiah Pohan ${ }^{3}$ \\ STIKOM Tunas Bangsa Pematangsiantar \\ Jl. Sudirman Blok A No. 1-3 Pematangsiantar, Sumatera Utara 21143, Indonesia \\ dwitaelisa01sinaga@gmail.com
}

\begin{abstract}
Food is the main need for humans, so the food business is growing, one of which is catering business. With the catering business it is increasingly easier for people to provide food needs at certain meetings or events. In carrying out its business, entrepreneurs must create different advantages to attract consumer interest. One effort to make the catering business run smoothly is by predicting the amount of income. One of the methods that can be used to solve this problem is the fuzzy Tsukamoto method. Where in this study using 3 variables, namely the ordering variable $(X)$ has a few and many fuzzy sets, the price variable $(Y)$ has an affordable and low set, and the income variable (Z) has a low and high set. The calculation results from the prediction of the amount of income that will be obtained by Sumatra culinary catering with 400 orders and the price of Rp. 13,000 is 4,620,000 per week.
\end{abstract}

Keywords: food, fuzzy, tsukamoto, business, catering, Pematangsiantar

Abstrak- Makanan adalah kebutuhan pokok bagi manusia, sehingga bisnis makanan semakin berkembang pesat salah satunya adalah usaha katering. Dengan adanya usaha katering semakin memudahkan masyarakat untuk menyediakan kebutuhan makanan dalam pertemuan atau acara tertentu. Dalam menjalankan usahanya para pengusaha harus menciptakan keunggulan yang berbeda untuk menarik minat konsumen. Salah satu upaya agar usaha katering berjalan lancar adalah dengan melakukan prediksi terhadap jumlah pendapatan. Salah satu metode yang dapat digunakan untuk memecahkan permasalahan tersebut adalah metode fuzzy Tsukamoto. Dimana dalam penelitian ini menggunakan 3 variabel yaitu variabel pemesanan $(X)$ memiliki himpunan fuzzynya sedikit dan banyak, variabel harga $(Y)$ memiliki himpunan terjangkau dan rendah, dan variabel pendapatan (Z) memiliki himpunan rendah dan tinggi. Hasil perhitungan dari prediksi jumlah pendapatan yang akan didapat katering Sumatra kuliner dengan pemesanan 400 dan harga Rp.13.000 adalah 4.620 .000 setiap minggunya.

Kata kunci: makanan, fuzzy, tsukamoto, usaha, katering, Pematangsiantar

\section{PENDAHULUAN}

Katering adalah sebuah usaha yang menyediakan jasa makanan siap saji yang dapat meringankan pekerjaan para konsumen dalam menyediakan makanan untuk kegiatan besar. Pada masa sekarang Usaha Katering sudah berkembang pesat, usaha ini memiliki peluang bagi seseorang yang memiliki kemampuan dan modal yang mencukupi. Dalam usaha Katering banyak orang yang beranggapan untuk memulai usaha Katering adalah hal terbaik dalam menyalurkan bakat memasak yang menjadikan uang dengan modal kecil menjadi laba besar. Saat ini banyak persaingan dalam usaha Katering tersebut sehingga para produsen menciptakan keunggulan yang berbeda untuk menarik para konsumen. Dalam menjalankan usaha Katering juga dibutuhkan prediksi pembukuan tentang 
seberapa besar pendapatan yang dihasilkan dari usaha Katering tersebut agar dapat menyeimbangkan antara pengeluaran dan juga pendapatan .

Sumatera Kuliner adalah salah satu usaha Katering yang berada dikota pematang siantar yang berlokasi d Jalan Kiay no. 14, Bantan, West Siantar, Pematang Siantar City, North Sumatera 21111. Sejak pertama dibukanya usaha Sumatera Kuliner, ouner hanya bisa memprediksi hasil pendapatannya dengan menggunakan perhitungan biasa. Sehingga permasalahan yang timbul adalah kesulitan dalam memprediksi jumlah pendapatan yang akan diterima agar usahanya dapat berjalan dengan lancar. Untuk dapat mengatasi permasalahan ini pengusaha Katering harus dapat memenuhi permintaan dan harga yang sesuai serta dapat menguntungkan kedua belah pihak antara produsen dengan konsumen,dengan menggunakan kecerdasan buatan. Salah satu metode dalam kecerdasan buatan yang dapat digunakan untuk prediksi adalah Fuzzy Logic [1].

\section{METODOLOGI PENELITIAN}

\subsection{Logika Fuzzy}

Logika fuzzy merupakan salah satu pembentuk soft computing. Logika fuzzy pertama kali diperkenalkan oleh Prof. Lotfi A. Zadeh pada tahun 1965. Dasar logika fuzzy adalah teori himpunan fuzzy. Pada teori himpunan fuzzy, peranan derajat keanggotaan sebagai penentu keberadaan elemen dalam suatu himpunan sangatla $\mathrm{h}$ penting [2]. Logika fuzzy memiliki derajat keanggotaan dalam rentang 0 hingga 1. Berbeda dengan logika digital yang hanya memiliki dua nilai 1 atau 0. Logika fuzzy digunakan untuk menerjemahkan suatu besaran yang diekspresikan menggunakan bahasa (linguistic)[3]

\subsection{Fuzzy Tsukamoto}

Fuzzy Tsukamoto merupakan salah satu metode dari Fuzzy Inference System. Dimana pada metode tsukamoto, setiap konsekuen pada aturan berbentuk if-then harus direprensetasikan dengan suatu himpunan fuzzy dengan fungsi keanggotaan yang monoton[4].

a. Fuzzifikasi adalah proses perhitungan yang dilakukan untuk mengubah variabel nyata menjadi variabel fuzzy.

b. Fuzzy Inferensi System adalah proses penggabungan beberapa aturan berdasarkan data yang telah tersedia. Sistem inferensi fuzzy merupakan suatu kerangka komputasi yang berdasarkan pada teori himpunan fuzzy, aturan fuzzy berbentuk IF-THEN.

c. Defuzzyfikasi adalah proses perhitungan yang dilakukan untuk mengubah variabel fuzzy kembali menjadi variabel nyata.

\section{HASIL DAN PEMBAHASAN}

Dengan menggunakan data yang diperoleh dari salah satu pengusaha Katering yang ada di kota Pematang Siantar yaitu Katering Sumatera Kuliner. Penulis Diminta untuk Menentukan Berapakah jumlah pendapatan perminggu jika pemesana $=400$ kotak dengan harga $=$ Rp. 13.000 perkotaknya. tahapan perhitungan yang harus dilakukan yaitu :

a. Menentukan Variabel Fuzzy 
Kriteria yang digunakan dalam menentukan pendapatan perminggu Terbagi menjadi 3 variabel yang ditunjukkn pada tabel 1.

Tabel 1. Variabel Fuzzy

\begin{tabular}{|c|c|}
\hline Variabel & Kode \\
\hline Pemesanan & $\mathrm{X}$ \\
\hline Harga & $\mathrm{Y}$ \\
\hline Pendapatan & $\mathrm{Z}$ \\
\hline
\end{tabular}

b. Menentukan Himpunan Fuzzy

Dalam menentukan himpunan fuzzy, penulis menggunakan 2 himpunan yang akan ditunjukkn pada tabel 2 .

Tabel 2. Himpunan Fuzzy

\begin{tabular}{|c|c|}
\hline Variabel & Himpunan Fuzzy \\
\hline Pemesanan & Sedikit \\
\cline { 2 - 2 } & Banyak \\
\hline Harga & Terjangkau \\
\cline { 2 - 2 } & Mahal \\
\hline Pendapatan & Rendah \\
\cline { 2 - 2 } & Tinggi \\
\hline
\end{tabular}

c. Fuzzy Fication

Terdapat 3 variabel yang akan dimodelkan menggunakan fungsi keanggotaan representasi linier, yaitu :

1. Pemesanan

Fungsi keanggotaan yang digunakan yaitu himpunan Sedikit Banyak dari variabel Pemesanan

$\mu X[$ Sedikit $]=\left\{\begin{array}{cc}0 & x<100 \\ \frac{550-x}{550-100} & 100<x<550 \\ 1 & x>550\end{array}\right.$

$\mu X[$ Banyak $]=\left\{\begin{array}{cc}0 & x>550 \\ \frac{x-100}{550-100} & 100<x<550 \\ 1 & x<100\end{array}\right.$

Nilai keanggotaan himpunan sedikit dan banyak dari variabel pesanan :

$$
\begin{aligned}
\mu \operatorname{Sedikit}(400)(\mathrm{x}) & =(550-400) / 450 \\
& =0,333333333 \\
\mu \operatorname{Banyak}(400)(\mathrm{x}) & =(400-550) / 450 \\
& =0,666666667
\end{aligned}
$$

2. Harga

Fungsi keanggotaan yang digunakan yaitu himpunan Sedikit Banyak dari variabel Harga :

$\mu y[$ Terjangkau $]=\left\{\begin{array}{cc}0 & y<12000 \\ \frac{20000-y}{20000-12000} & 12000<y<20000 \\ 1 & y>20000\end{array}\right.$ 
$\mu y[$ Mahal $]=\left\{\begin{array}{cc}1 & y<12000 \\ \frac{y-12000}{20000-12000} & 12000<y<20000 \\ 0 & y>20000\end{array}\right.$

Nilai keanggotaan himpunan sedikit dan banyak dari variabel pesanan :

$\mu$ Terjangkau $(13.000)(y)=(20000-13000) / 8000$

$$
=0,875
$$

$\mu \operatorname{Mahal}(13.000)(y)=(13000-12000) / 8000$

$$
=0,125
$$

3. Pendapatan

Fungsi keanggotaan yang digunakan yaitu himpunan Sedikit Banyak dari variabel Pendapatan :

$$
\begin{aligned}
& \mu y[\text { Rendah }]=\left\{\begin{array}{cc}
0 & z<1.200 .000 \\
\frac{6.600 .000-z}{6.600 .000-1.200 .000} & 1.200 .000<z<6.600 .000 \\
1 & z>6.600 .000
\end{array}\right. \\
& \mu y[\text { Tinggi }]=\left\{\begin{array}{cr}
1 & z<1.200 .000 \\
\frac{z-1200.000}{6600000-1200000} & 1.200 .000<z<6.600 .000 \\
0 & z>6.600 .000
\end{array}\right.
\end{aligned}
$$

d. Membuat Fuzzy Rule

Proses ini berfungsi untuk mencari suatu nilai fuzzy input yang berasal dari proses fuzzyfication kemudian dimasukkan ke dalam sebuah rule yang telah dibuat untuk dijadikan sebuah fuzzy output.

Tabel.2 Fuzzy Rule

\begin{tabular}{|l|l|l|l|}
\hline Rule & Permintaan & \multicolumn{1}{|c|}{ Harga } & Pendapatan \\
\hline 1 & Sedikit & Mahal & Rendah \\
\hline 2 & Sedikit & Terjangkau & Rendah \\
\hline 3 & Banyak & Mahal & Tinggi \\
\hline 4 & Banyak & Tarjangkau & Tinggi \\
\hline
\end{tabular}

Perhitungan untuk mencari nilai dari $\alpha$-predikat yakni :

Rule 1:

$\alpha$-predikat $=\min (0.333333 ; 0,125)$

$$
\mathrm{Z}=0,125
$$

$$
\begin{array}{ll}
0,125 & =\frac{6.600 .000-x}{5.400 .000} \\
6.600 .000-x & =0,125 * 5.400 .000 \\
6.600 .000-x & =675.000 \\
-x & =675.000-6.600 .000
\end{array}
$$




$\begin{array}{ll}-\mathrm{X} & =-5.925 .000 \\ \mathrm{X} & =5.925 .000\end{array}$

Rule 2:

$\alpha$-Predikat $=\min (0,33333 ; 0,875)$

$\mathrm{z} \quad=0,333333$

$\begin{array}{ll}0,333333 & =\frac{6.600 .000-x}{5.400 .000} \\ 6.600 .000-x & =0,333333 * 5.400 .000 \\ 6.600 .000-x & =1.800 .000 \\ -x & =1.800 .000-6.600 .000 \\ -x & =-4.800 .000 \\ X & =4.800 .000\end{array}$

Rule 3:

$\alpha$-Predikat $=\min (0,666667 ; 0,125)$

$\mathrm{z} \quad=0,125$

$$
\begin{array}{ll}
0,125 & =\frac{x-1 \cdot 200.000}{5.400 .000} \\
X-1.200 .000 & =0,125 * 5.400 .000 \\
6.600 .000-x & =675.000 \\
x & =675.000+1.200 .000 \\
x & =1.875 .000
\end{array}
$$

Rule 4:

$\alpha$-Predikat $=\min (0,666667 ; 0,875)$

$\mathrm{z} \quad=0,666667$

$$
\begin{array}{ll}
0,666667 & =\frac{x-1 \cdot 200.000}{5.400 .000} \\
X-1.200 .000 & =0,666667 * 5.400 .000 \\
6.600 .000-x & =3.600 .000 \\
X & =3.600 .000+1.200 .000 \\
x & =4.800 .000
\end{array}
$$

e. DeFuzzyFikasi

$$
\begin{aligned}
Z & =\frac{(0,125 * 5.925 .000)+(0.333333 * 4.800 .000)+(0,125 * 1.875 .000)+(0,666667 * 4.800 .000}{(0,125+0,333333+0,125+0,666667)} \\
& =\frac{740.625+1.600 .000+234.375+3.200 .000}{1,25} \\
& =\frac{5.775 .0000}{1,25} \\
& =\operatorname{Rp} 4.620 .000
\end{aligned}
$$


Jadi menurut perhitungan ini dapat dikatakan bahwa pendapatan Perminggu yang dihasilkan oleh Katering Sumatera Kuliner berkisar Rp 4.620.000 setiap minggunya.

\section{KESIMPULAN}

Berdasarkan pembahasan mengenai Metode Fuzzy Tsukamoto dengan data yang diterima dari Katering Sumatera Kuliner dalam memprediksi besar pendapatan perminggu, dilakukan dengan menggunakan tiga variabel yaitu Pemesanan,Harga dan Pendapatan. Dari hasil perhitungan yang telah di lakukan maka dapat diprediksi bahwa pendapatan perminggu yang akan diterima oleh Katering Sumatera Kuliner adalah Rp 4.620.000, jika konsumen melakukan pemesanan sebanyak 400 kotak dengan harga Rp 13.000,-.

\section{DAFTAR PUSTAKA}

[1] J. Produksi, R. Pada, and C. V Gendis, "Sistem berbasis aturan menggunakan logika fuzzy tsukamoto untuk prediksi jumlah produksi roti pada cv. gendis bakery."

[2] A. Wanto, "Analisis Penerapan Fuzzy Inference System (FIS) Dengan Metode Mamdani Pada Sistem Prediksi Mahasiswa Non Aktif (Studi Kasus : AMIK Tunas Bangsa Pematangsiantar)," in Seminar Nasional Inovasi Dan Teknologi Informasi (SNITI) 3, 2016, vol. 3, pp. 393-400.

[3] L. P. Ayuningtias, "ANALISA PERBANDINGAN LOGIC FUZZY METODE TSUKAMOTO , SUGENO , DAN MAMDANI ( STUDI KASUS : PREDIKSI JUMLAH PENDAFTAR MAHASISWA BARU FAKULTAS SAINS DAN TEKNOLOGI UNIVERSITAS ISLAM NEGERI SUNAN GUNUNG DJATI BANDUNG )," no. April, 2017.

[4] Y. R. W. U. Kurnia Martha Herdiastuti, Bebas Widada, "IMPLEMENTASI ALGORITMA FUZZY TSUKAMOTO UNTUK MENENTUKAN JUMLAH PRODUKSI ROTI,” pp. 23-29.

[5] A. P. Windarto, "Penerapan Data Mining Pada Ekspor Buah-Buahan Menurut Negara Tujuan Menggunakan K-Means Clustering,” Techno.COM, vol. 16, no. 4, pp. 348-357, 2017. 